\title{
CONSIDERACIONES PARA UN ENFOQUE HISTORICO-EPISTEMOLOGICO DE LA ENSEÑANZA DE LAS CIENCIAS.
}

\author{
Juan Carlos Orozco C. \\ Profesor catedrático \\ Departamento de Física. \\ Universidad Pedagógica Nacional
}

En su introducción a la "Filosofía del No", Gaston Bachelard sostiene que "... la filosofía de las ciencias permanece demasiado a menudo acantonada en las dos extremidades del saber: en el estudio de los principios demasiado generales por parte de los filósofos, y en el estudio de los resultados demasiado particulares por parte de los científicos. La filosofía de la ciencia se agota contra los dos obstáculos epistemológicos ${ }^{1}$ contrarios que limitan todo pensamiento: lo general y lo inmediato. Valoriza a veces lo a priori, a veces lo a posteriori, desconociendo las transmutaciones de valores epistemológicos entre lo a priori y lo a posteriori, entre los valores experimentales y los valores racionales, transmutaciones que el pensamiento científico contemporáneo opera sin cesar."2. Mutatis mutandi, podríamos sostener similares "observaciones" con respecto a la Historia de las ciencias.

Nada más apropiado entonces que partir de estas consideraciones, globales pero así mismo esclarecedoras, para iniciar la aproximación a la definición de un espacio históricoepistemológico para la enseñanza de las ciencias, en el cual la pregunta trivial: ¿Aportan algo los estudios históricos y filosóficos sobre el desarrollo del conocimiento científico en la dirección de una pedagogía de las ciencias?, pueda ser redimensionada y a partir de ella sea dable caracterizar aquel ámbito de transmutaciones, aquel espacio para la resolución de las contradicciones entre "lo general y lo inmediato", que las reflexiones bachelardianas precisan definir.

Por otra parte, y en virtud de las nuevas dimensiones que asumiría nuestra pregunta, se demanda clarificar los nexos entre la historia y la filosofía de las ciencias y determinar la región de reflexión epistemológica y de análisis crítico del conocimiento científico en donde ambas disciplinas se apoyan mutuamente en la medida en que: "la historia [contribuye] a salvar la brecha que hay entre los filósofos de la ciencia y la propia ciencia" ${ }^{3}$ y la filosofía, por su parte, aproxima la historia a la "reconstrucción racional" ${ }^{4}$ del conocimiento científico.

\section{Aportes a una pedagogía de las ciencias desde la historia y la filosofía de las ciencias.}

\footnotetext{
${ }^{1}$ Sobre la noción de obstáculo epistemológico véanse:

BACHELARD, G., "La formación del espíritu científico", Siglo XXI Editores.

LECOURT, Dominique., "Para una crítica de la epistemología"., Siglo XXI Editores.

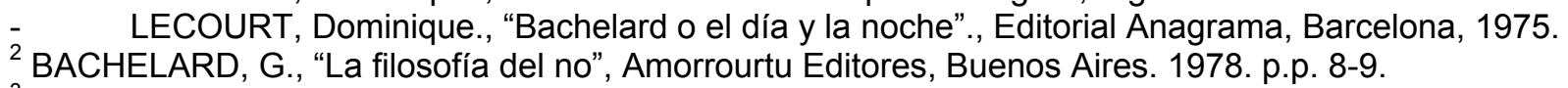

${ }^{3}$ KUHN, Thomas., "La tensión esencial", Fondo de Cultura Económica, México, 1987, pp. 37. Los corchetes son nuestros.

${ }^{4}$ lbid., p.p. 38
} 
Hemos planteado, y hoy por hoy es un hecho aceptado sin mayores reparos, que los estudios histórico-epistemológicos aportan y de suyo tienen mucho que aportar a la enseñanza de las ciencias y a la formulación de un pedagogía científica, esto es de una pedagogía solidaria con la formación del espíritu científico. No obstante, si nos conformásemos con esta especie de "acto de fe" poco avanzaríamos en la empresa orientada a consolidar la cultura científica, aspecto que se halla íntimamente ligado a la dialéctica planteada por Bachelard con respecto a la filosofía de las ciencias y extendible, en nuestro contexto teórico, a la historia de las mismas.

Se requiere, entonces, hacer explícitos, así sea de manera hipotética en un primer intento, los principales aportes que, tanto desde la historia, como desde la epistemología y los umbrales metateóricos en donde ambas se confunden, se hacen a la enseñanza de las ciencias y, por la dinámica propia del superracionalismo ${ }^{5}$, a la estructura misma del conocimiento científico. Consideremos, pues, por el momento las siguientes.

- Los estudios a que nos referimos proporcionan una variada información sobre las circunstancias históricas y los contextos de pensamiento en que surgieron las teorías científicas. De esta manera, por ejemplo, nos es posible apreciar la consolidación de una teoría química como El Flogisto en un época en la cual la visión substancialista proyectada sobre muchos de los fenómenos naturales se encontraba en el seno de las discusiones científicas y se asumía como indispensable para explicar fenómenos asociados con la transformación de los cuerpos (combustión, calcinación de los metales, respiración).

- Nos permiten rastrear el curso que siguen los conceptos y teorías de la ciencia hasta su estado actual de consolidación. Al respecto, un concepto como el de átomo manifiesta el apasionante tránsito de una idea que, intuida y forjada a la luz de las consideraciones teoréticas de los filósofos presocráticos, llega a adquirir entidad material bajo las teorías corpusculares del siglo XIX y adquiere una entidad ontológica particular bajo la axiomática teórica y experimental de la ciencia del presente siglo.

El aspecto aquí enunciado nos aproxima, además, a la noción bachelardiana de perfil epistemológico ${ }^{6}$ y nos posibilita asumirla en el campo de la didáctica de las ciencias, así como orientarla hacia la definición, caracterización y resolución de los obstáculos pedagógicos ${ }^{7}$. En este sentido, rastrear el curso de los conceptos y las teorías con todos sus altibajos, reconociendo sus discontinuidades y contradicciones, conduce al docente a las esferas en donde debe asumir la tarea de una especie de geólogo del pensamiento científico, en donde debe reconocer en la pedagogía una pedagogía de la razón, esto es una pedagogía que aprovecha "todas las ocasiones de razonar"8.

\footnotetext{
${ }^{5}$ Sobre la concepción de superracionalismo véase: BACHELARD, G., "La Filosofía del no", op. cit., p.p. 9 s.s.

${ }^{6}$ Véase al respecto, Ibid., Cap. II, p.p. 36-44

${ }^{7}$ Con respecto a esta noción bachelardiana es mucho y muy confuso cuanto se ha dicho y hay bastante por decir todavía, en parte porque el mismo Bachelard ("La formación del espíritu científico", op. cit., p.p. 19) apenas plantea el problema sin sugerir mayores posibilidades para abordarlo y menos todavía para resolverlo. Cfr.: OROZCO, - Juan Carlos. SOTO Carlos A., "Una aproximación pedagógica al estudio de la estructura conceptual de la Química", monografía de grado, Universidad Pedagógica Nacional, Departamento de Química, Bogotá, 1986, p.p. 29-34. SOTO Carlos A., "Diseño y aplicación de un modelo epistemológico sobre el pensamiento post-formal fundamentado en el contexto cuántico", Tesis de grado de Magister en Docencia de la Química, U.P.N., Bogotá, 1990, pp. 8-11.
}

${ }^{8}$ Bachelard. G. "la filosofía del no", op. cit., op. 119 
- Dichos estudios nos aportan elementos de juicio para auscultar la lógica que subyace a las teorías científicas en particular y al conocimiento científico en general, permitiéndonos aducir un nuevo elemento diferenciador frente a otras formas de conocimiento; posibilitándonos de paso dilucidar las fronteras entre las lógicamatemáticas y posibilidades lógicas particulares de las formas discursivas de la ciencia; aproximándonos además a aceptar el papel que en un plano paralógico juegan el azar y el acaso en muchos de los descubrimientos científicos y que, precisamente en virtud de esa paralógica, llegan a ser racionalizados y elevados a las categorías propias del discurso científico. Mucho ilustran en este sentido el descubrimiento de la ley periódica y la construcción de la tabla de los elementos químicos, impresionantes empresas de lógica racionalista y de pluralismo coherente ${ }^{9}$ en palabras de Bachelard; mucho aporta, en otra dirección, la formulación de la estructura hexagonal del Benceno por parte de Kekulé, uno de los más apasionantes logros de la química estructural y ejemplo esclarecedor de intuición trabajada ${ }^{10}$.

- Nos posibilitan caracterizar las diferencias discursivas entre las diversas ciencias experimentales y los estatutos comunes a los diferentes discursos científicos. De paso nos proporcionan los elementos de juicio indispensables para apreciar detrás de cada gran teoría una cosmovisión particular, para rastrear los soportes argumentales en virtud de los cuales nos es dado reconocer las diferencias taxativas que, en su forma de abordar el mundo presentan sistemas teóricos como la mecánica newtoniana, la mecánica relativista y la mecánica cuántica.

En este contexto es en donde tal vez más pueden expandirse los alcances de los estudios histórico-epistemológicos pero, así mismo, es en donde menos esclarecedoras se presentan las acciones desde y hacia la pedagogía. Extenso, en efecto, se presenta el camino por recorrer en la dirección de los nexos entre discurso científico y sentido, entre simbolismo y significación al interior de la ciencia, entre traducibilidad conceptual e inconmensurabilidad teórica ${ }^{11}$, por sólo citar en tono especulativo algunas relaciones. Relaciones que, dicho sea de paso, comportan profundas implicaciones pedagógicas.

- Nos acercan a las formas específicas de producción que se dan al interior de la ciencia, familiarizándonos de paso con la labor del científico. En este plano resulta de suma importancia la labor de esclarecimiento en torno a estereotipos y arquetipos que han llegado a imponerse con respecto a la labor científica y los cuales desvirtúan casi sin proponérselo una imagen de ciencia concordante con un espíritu abierto, solidaria con una mente creativa. Se hace posible, por otra parte, recuperar "lo humano" en el hombre de ciencia, evidenciar que "el conocimiento y perfeccionamiento científico es consecuencia del pensar de miles de mentes humanas, falibles sí, pero sin duda maravillosas"12. Se nos permite, igualmente, desmitificar la imagen sacra con que se ha revestido el método científico en la práctica educativa de la ciencia, deificación que

${ }^{9}$ BACHELARD G., "Epistemología”, selección de Dominique Lecourt., Editorial Anagrama, Barcelona 1974. p.p. 92 s.s.

${ }^{10}$ Cfr. SERRATOSA, Félix., "Khymós", Editorial Alambra S.A., Madrid 1969.

${ }^{11}$ Con respecto a estos dos conceptos (traducibilidad e inconmensurabilidad), véanse:

- FEYERABEND, Paul., "Límites de la ciencia", Ediciones Paidos Ibérica S.A., Barcelona, 1989. p.p. 112, S.S.

- KUHN, Thomas., "¿Qué son las revoluciones científicas? y otros ensayos" Ediciones Paidos Ibérica SA., Barcelona. 1989. PP. 95, s.s.

${ }^{12}$ ASIMOV, Isaac., "Enciclopedia biográfica de ciencia y tecnología”, vol I.,Editorial Alianza, Madrid, 1897, p.p. ix. 
en nuestro medio constituye una barrera casi infranqueable para la producción de nuevos sabores; mistificación que se ha venido refinando con el tiempo apoyada por los desarrollos desiguales entre las nuevas didácticas y las prácticas escolares concretas $^{13}$.

- Nos aproximan a la comprensión de las características que engloban las comunidades científicas; aspecto éste de gran importancia para analizar y entender la producción de conocimiento científico en nuestros días y la naturaleza colectiva que caracteriza toda empresa científica. Sin contemplar este elemento, desconociendo lo social dinámico que subyace a una ciencia inmersa en la cultura contemporánea, bien difícil nos sería asimilar en toda su complejidad el curso que se sigue desde el descubrimiento de la radioactividad hasta la explosión de la primera bomba atómica. Especiales características reviste este aporte desde los estudios histórico-epistemológicos en sociedades que, como la nuestra, aún permanecen al margen de la cultura universal científica en términos de producción de nuevos saberes. En este sentido cobra trascendencia ver que "la ciencia es alga realizado cooperativamente por persona; (y que) por eso deben tenerse en cuenta, de forma preferencial, además de las convicciones empíricas y especulativas de los individuos, las estructuras sociológicas y las convicciones que unen entre sí a los científicos." 14

Digamos, finalmente, que nos permiten entrever los procesos de transmisión, transferencia y legitimación de los conocimientos habidos en el seno de la ciencia, así como el papel que la pedagogía en cuanto reflexión sobre la enseñanza y la escuela en tanto espacio de socialización han jugado en la consolidación de tal o cual forma de conocimiento y en la validación social o no de éstas u otras teorías. Se resalta aquí un hecho rara vez apercibido, el carácter no pasivo de lo pedagógico frente a lo científico, la síntesis espacio-temporal que suele darse entre escuela y laboratorio.

Como puede apreciarse, en los aspectos arriba enunciados se plantea la necesidad de racionalización, bajo los parámetros de un racionalismo aplicado ${ }^{15}$, por parte del maestro en ciencias en torno a los fundamentos didácticos que se encuentran en la base de los estudios histórico-epistemológicos; se sigue, igualmente, la factibilidad de su inclusión en la práctica docente cotidiana como elementos dinamizadores de una pretendida pedagogía de lo científico. En este sentido, dos elementos aparecen a primera vista como potencialmente enriquecedores de una práctica docente para y en la formación del espíritu científico:

1. El elemento autotélico ${ }^{16}$ subyacente a la relación entre los contenidos de la ciencia y los aspectos vinculados a la cotidianeidad del estudiante. Relación en donde las contradicciones entre lo "general y lo inmediato", entre "lo próximo y lo profundo", empiezan a resolverse en la medida que se caracterizan espacios de riesgo reduccionista y se recuperan intuiciones creadoras; en la medida en que se recrea una ciencia viva que también da cuenta del hombre y, en su debido plano, constituye una posibilidad de realización humana. En esta perspectiva, el manido problema entre

\footnotetext{
${ }^{13}$ Cfr., por ejemplo, GIL P. Daniel., "Tres paradigmas básicos en la enseñanza de las ciencias"., Revista Enseñanza de las Ciencias, Año 1, No. 1, Barcelona, 1983.

${ }^{14}$ SCHAFER, Lothar - Thomas ACHNELLE., en la introducción a: FLECK, Ludwik, "La génesis y el desarrollo de un hecho científico", Editorial Alianza, Madrid, 1986, p.p. 22. Los paréntesis y el subrayado son nuestros

${ }^{15}$ Véase: BACHELARD, G., "Epistemología", op. cit., p.p. 127 s.s.

${ }^{16}$ Esto es, el elemento automotivante, en virtud del cual el estudiante no es un ser desprevenido frente al conocimiento científico, por el contrario acude a la escuela con una intencionalidad y actitud a las cuales la escuela debería responder solidariamente
} 
sentido común y lógica científica, entre conocimiento cotidiano y conocimiento científico, adquiere una nueva dimensión y la labor pedagógica no se circunscribe ya al simple ejercicio para transformar unas formas de racionalidad en otras, para superar unos saberes profusos y poco sistemáticos en beneficio de otros más coherentes y discursivamente sistemáticos; muy por el contrario, apuntaría dicha labor al aspecto que hemos señalado desde un comienzo: la formación de un espíritu científico y la concepción de una práctica escolar concordante con éste.

2. El elemento holístico que comporta una ciencia "autosuficiente" en su capacidad de comprender un universo elaborado sobre sólidas bases racionalistas pero no excluyente en el sentido que permite relacionar sus contenidos con otras disciplinas y espacios epistémicos con universos propios posibles de construir. Capacidad universalizante que se desprende de una ciencia conocedora de su extraordinario potencial heurístico pero reconocedora de sus yerros y limitaciones.

Lo holístico habrá de traducirse, justamente, en una imagen de ciencia que supera la tendencia a la compartamentalización de los conocimientos y a la jerarquización vertical de los contenidos a abordar en la escuela. Se acepta, por otra parte, la necesidad de Unidad y Globalidad como elementos de suma importancia para comprender la complejización ${ }^{17}$ de las disciplinas científicas, su acceso a nuevas imágenes y representaciones, su aproximación a nuevas formas de racionalidad, a la construcción de nuevos mundos.

Sin embargo, nuestras consideraciones no se agotan aquí. Hemos planteado, en efecto, una "dirección" en los aportes de los estudios históricos y filosóficos de las ciencias. Una "dirección" que debe verse complementada con caminos alternos, con rutas retrospectivas, con "re-direcciones" correspondientes; caminos y rutas que procuraremos abordar en el apartado siguiente.

\section{La historia y la filosofía de las ciencias como pedagogía científica.}

Hemos de ocuparnos ahora de algunos aspectos fundamentales que, entre otros, suelen pasar desapercibidos o bien se desvirtúan cuando el papel de la historia y la filosofía de las ciencias en el contexto pedagógico se orientan a lo exclusivamente metodológico, a una bien intencionada pero no siempre bien concebida didáctica de las ciencias. Para tales fines se hace necesario explicitar una tesis que por el momento se halla dispersa en las entrelíneas de este escrito y ella es: como espacio para la reflexión sobre el conocer científico, la pedagogía de las ciencias comporta el contexto en donde saberes científicos, historia y filosofía de las ciencias, pedagogía y didáctica, se interrelacionan en una unidad totalizante y coadyuvan, en sus múltiples nexos, a la dinámica del conocimiento.

El reconocimiento de esta tesis plantea la necesidad de destacar un papel de la historia y la epistemología que, usualmente, no cuenta para el maestro de ciencias (casi siempre como consecuencia de un conocimiento parcial o de una mirada sesgada de las relaciones a que hemos hecho referencia) y que, en virtud de compromisos teóricos inflexibles, no suele ser considerado por el historiador o el filósofo de las ciencias. Nos referimos a la función de análisis de los procesos de producción de conocimiento científico y de cuestionamiento a las prácticas pedagógicas que le subyacen en cuanto

\footnotetext{
${ }^{17}$ El uso del término "complejo" suele conducir a múltiples confusiones, una de ellas es asimilarlo a "difícil" o a "super-ordenado"; no es ésta la acepción con la cual lo contemplamos aquí, se pretende más bien referimos a una mayor "sistematización" y a una más elevada capacidad heurística.
} 
procesos de construcción y apropiación de saberes. En este sentido, resulta prioritario reconocer que en toda práctica educativa mediada por una concepción pedagógica determinada se hallan implícitos una visión particular de la ciencia y un trasfondo epistemológico específico. Debemos hacer hincapié, al respecto, que no se trata simplemente de la concepción de ciencia individual del maestro, del filósofo o del historiador ni de sus compromisos epistemológicos personales, sino de aquellos elementos fundamentantes subsumidos en la "razón social" de las prácticas educativas y científicas $^{18}$

Correlativamente, en toda práctica científica se halla inmersa una determinada "pedagogía", a manera de conciencia oculta de la naturaleza "educativa" inherente a la empresa científica y en función de la cual la labor de los hombres de ciencia -y de los colectivos científicos- comporta múltiples compromisos, no circunscritos exclusivamente a la búsqueda de una "verdad" perfectible o al goce estético que bien puede proporcionar la disposición axiomática de una teoría.

La función arriba enunciada, asumida en propiedad, permite por otro lado plantear la importancia crucial que tanto la historia como la epistemología adquieren como potenciadoras del trabajo al interior mismo de las disciplinas científicas en la medida en que permiten establecer nuevos espacios problemáticos, identificar prácticas alternativas, sugerir la pertinencia de modelos que en un momento determinado resultaron inadecuados pero a la luz de los nuevos desarrollos teóricos y en consonancia con las nuevas exigencias aparecen consistentes y válidos, y recuperar supuestos teóricos que en su momento pasaron desapercibidos o bien se dejaron de lado en tanto se asumían otras prioridades.

Como bien puede inferirse, la tarea de la historia y la epistemología no se reduce a la labor de dos disciplinas pasivas ante cuyos fundamentos transcurren las realizaciones de la ciencia para ser contempladas en su devenir histórico y en su entronque sistemático en la dinámica social, por una parte, o para ser analizadas y diseccionadas en su constitución interna, así como interpretadas en una u otra dirección del pensamiento, por otro lado. Por el contrario, ambas desempeñan una minuciosa labor estrechamente vinculada al desarrollo y consolidación del conocimiento científico; por su reconocida capacidad de crítica racional y su moderado escepticismo constituyen una fuente permanente de cuestionamientos e ideas novedosas para la empresa científica, y en esta medida se consolidan como una posibilidad para acceder a las fronteras del conocimiento científico cuando las precariedades tecnológicas constituyen una barrera, a primera vista, infranqueable. Gracias a la constatada flexibilidad de su discurso y a su rigurosa amplitud de visiones, proporcionan un espacio adecuado para la confrontación teórica en aras a la resolución de los problemas y contradicciones inherentes a la gesta científica, así como para la reflexión imaginaria que hace posible la construcción de nuevas realidades a partir de la ensoñación recreada y la práctica sistemática de la utopía, entendida ésta como discurso de lo posible. En este plano, los estudios histórico-epistemológicos nos posibilitan asumir las sutiles diferencias discursivas que empiezan a presentarse entre los diferentes campos del conocimiento y las diversas formas de interpretación del mundo características de finales de este siglo.

\footnotetext{
${ }^{18}$ Esta situación se desprende, hipotéticamente, de la naturaleza colectiva de las empresas científicas y educativas, mucho más en la época contemporánea.
}

Cfr. FLECK. Ludwik.. op. c,t. pp. 85 s.s. 